\title{
T Cell Receptor $\beta$-Chain Gene Rearrangement without $\gamma$-Chain Gene Rearrangement in Cutaneous T Cell Lymphoma: An Unusual Finding ${ }^{1}$
}

\author{
Vincent C. Ho, ${ }^{*}, 2$ Erik R. Hansen, $\dagger$ James T. Elder, ${ }^{*}$ Ole BaAdsgaard, \\ Gunhild L. VejlsgaArd, † Curtis A. Hanson, $\ddagger$ and Kevin D. Cooper* \\ The Department of ${ }^{*}$ Dermatology and $\ddagger$ Pathology, University of Michigan, Ann Arhor, Michigan \\ 48109, and the Department of +Dermatology, Bisbebjerg Hospital, University of Copenhagen
}

$\mathrm{T}$ cells from the blood and skin of a patient with cutaneous $\mathrm{T}$ cell lymphoma demonstrated rearrangement of the $T$ cell receptor $\beta$-chain gene in the absence of rearrangement of the $\gamma$-chain gene. To our knowledge, this has not been previously reported. This finding was unexpected in light of prevailing concepts of $T$ cell ontogeny. Potential explanations for it are discussed. 1990 Academic Press, Inc.

\section{INTRODUCTION}

$\mathrm{T}$ cells express antigen-specific receptors on their surface. The $\mathrm{T}$ cell receptor (TCR) expressed by most mature peripheral $\mathrm{T}$ cells has been characterized as a heterodimer consisting of $\alpha$ and $\beta$ chains. The cDNAs encoding these chains have been cloned and are composed of variable-, diversity-, joining-, and constantregion gene segments. These segments undergo rearrangement during thymic development of $T$ cells, analogous to the immunoglobulin rearrangement characteristic of B cells. This process generates a unique receptor for each clonally derived $\mathrm{T}$ cell population.

In addition to genes encoding for the $\alpha$ and $\beta$ subunits of the TCR, additional genes have been discovered to encode for a $\gamma$ chain and its partner $\delta$ chain. Each of these genes consists of variable-, joining-, and constant-region genes which also rearrange during $\mathrm{T}$ cell development, albeit with less potential for diversity.

Studies of fetal thymocytes demonstrate that the TCR- $\gamma / \delta$ heterodimer is the first receptor to appear in thymic ontogeny, preceding the TCR- $\alpha / \beta$ by $2-3$ days (1). Analysis of TCR gene rearrangements in human T cell leukemias and lymphomas has shown TCR- $\gamma$ gene rearrangements in the absence of TCR- $\beta$ gene rearrangements $(2-6)$. These data have been used to support the prevailing concept that $\gamma$-chain gene rearrangements precede $\beta$-chain gene rearrangements in $T$ cell ontogeny. It has been proposed that $T$ cells initially rearrange the $\gamma$ - and $\delta$-chain genes. If successful, and functional protein is made, rearrangements of $\alpha$ -

\footnotetext{
${ }^{1}$ This work was supported in part by NIH Grant AR01770-02 (K.D.C.). Dr. Ho was a recipient of the R. S. McLaughlin Research Fellowship from Canada during this study.

${ }^{2}$ Currently affiliated with the Division of Dermatology, University of British Columbia, Vancouver, Canada.
} 
and $\beta$-chain genes do not occur, and a $\gamma / \delta$-chain TCR is expressed. If a functional protein is not produced, $T$ cells will then go on to rearrange the $\alpha$ - and $\beta$ - chain genes.

We report here a case of cutaneous $T$ cell lymphoma in which the malignant $T$ cells demonstrated a TCR- $\beta$ gene rearrangement in the absence of a TCR- $\gamma$ gene rearrangement. Thus, this experiment of nature is in apparent contradiction to the existing concept of $T$ cell ontogeny. Potential explanations for this unusual finding will be discussed.

\section{PATIENTS AND METHODS}

\section{Case Report}

A 70-year-old man presented with an 11-year history of erythematous, scaly patches on the face and back. At the time of presentation, the eruption had become more widespread and he had developed several plaques on the back. The physical examination was otherwise unremarkable. In particular, there were no lymphadenopathy or organomegaly. Investigations revealed marked leukocytosis $\left(50.0 \times 10^{9} /\right.$ liter; normal range 3.0-9.0 $\times 10^{9} /$ liter) with greater than $90 \%$ atypical leukemic Sezary cells. The following tests were within normal limits: hemoblobin, red cell indices, platelet count, prothrombin time, partial thromboplastin time, blood urea nitrogen, serum creatinine, total protein, serum protein electrophoresis, serum immunoglobulins, serum albumin, total bilirubin, lactate dehydrogenase, alkaline phosphatase, aspartate aminotransferase, alanine aminotransferase, uric acid, triglycerides, cholesterol, calcium, phosphorus, magnesium, urinalysis, and chest radiograph. Multiple skin biopsy specimens showed the same histological pattern of a dense dermal infiltrate consisting of atypical lymphocytes and multiple Pautrier microabscesses. These histological findings were diagnostic of cutaneous $\mathrm{T}$ cell lymphoma. Immunohistochemical studies revealed that the malignant infiltrate was entirely of the Thelper $\left(\mathrm{CD} 3^{+} \mathrm{CD} 4^{+} \mathrm{CD} 8^{-}\right)$phenotype.

\section{DNA Blot Hybridization Analysis}

High molecular weight DNA was extracted from a 6-mm punch biopsy specimen of a CTCL skin tumor and from peripheral blood mononuclear cells isolated by Ficoll-Hypaque centrifugation and purified by detergent lysis, proteinase $\mathrm{K}$ digestion, and phenol extraction as previously described (7). For each sample, 7.5 $\mu \mathrm{g}$ of DNA was digested with EcoR1, HindIII, or BamHI restriction endonucleases, size-fractionated by electrophoresis on a $0.8 \%$ agarose gel, and then transferred to nylon filters (Zeta Probe, Bio-Rad) by the technique of Southern (8). ${ }^{32} \mathrm{P}$-labeled cDNA probes were prepared by random priming (9) and the filters were hybridized under stringent conditions and autoradiographed as previously described (10). DNA isolated from the $T$ cell lymphoblastic leukemia cell lines, Jurkat and Molt-4, and from Scl-1, a squamous cell carcinoma cell line, were used as internal controls for rearranged and germline DNA, respectively. 


\section{DNA Probes}

Rearrangements of the TCR- $\beta$-chain gene were detected by a 400 basepair (bp) Ava I/PstI fragment of the cDNA clone YT35 (11) (a gift of Dr. T. Mak). This probe, designated $c \beta 1$, hybridizes to both constant regions of the TCR- $\beta$ gene.

TCR- $\gamma$ gene rearrangements were mapped by hybrization with a 700-bp HindIII/EcoR1 fragment of human genomic DNA clone M13H60 (12) (a gift of Dr. T. H. Rabbitts). This probe, designated $\mathrm{j} \gamma 1$, can detect hybridizations to both joining regions 1 and 2 of the TCR- $\gamma$-chain gene.

Rearrangements of the immunoglobulin heavy chain $(\mathrm{Ig} \mathrm{H})$ gene were detected with a $\mathrm{jH}$ probe; this probe consists of a $6.0-\mathrm{kb}$ Bam HI/HindIII fragment containing the joining region of the Ig $\mathrm{H}$ chain, as previously described (13).

\section{RESULTS}

DNA blots of EcoR1, HindIII, and BamHI digests of the patient's genomic DNA were hybridized against the TCR- $\beta$ constant region probe and demonstrate rearrangement of the TCR- $\beta$-chain gene of the malignant T cells in the blood (Fig. 1, panels III, V) and skin (Fig. 1, panel IV) of this patient. The absence of the 11.0-kb EcoR1 band (Fig. 1, panel I) and the marked reduction in the intensity of the 4.0-kb HindIII band (Fig. 1, panel III) in the blood specimen suggest that both chromosomes have rearranged and that the malignant clone comprises a large proportion of the peripheral blood mononuclear cells. DNA isolated from the skin

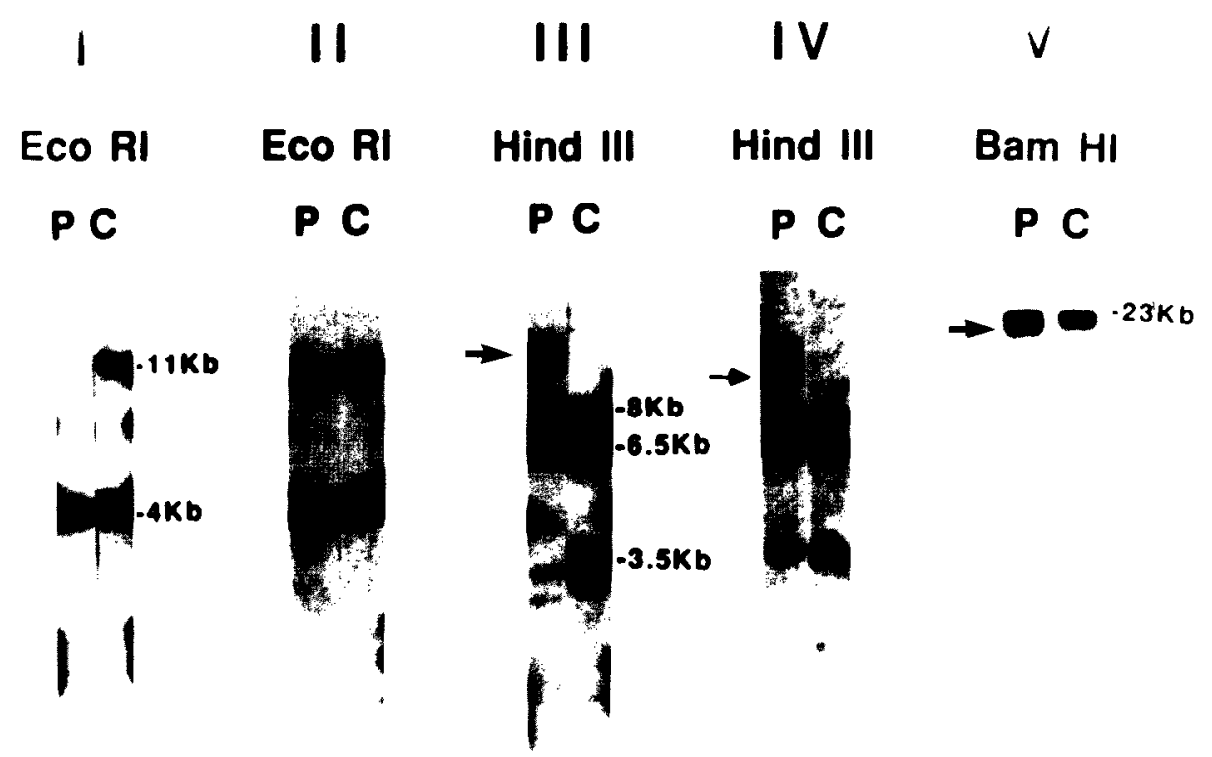

Fig. 1. Southern blot hybridization analysis of the T cell receptor $\beta$ chain genes (TCR- $\beta$ ). DNA analysis of the patient's blood (I, III, V) and skin lesion (II and IV) with the TCR- $\beta$ probe, $c \beta 1$, after digestion with EcoR1, HindIII, and BamHI. P represents the patient's specimen and C represents the control specimen. Dashes indicate germline bands in kilobases. Arrows point to the rearranged bands. 
displays the same pattern as that detected in the blood specimen, except the intensity of the 11.0-kb EcoR1 and 4.0-kb HindIII bands (Fig. 1, panels II, IV) is increased, reflecting the presence of keratinocytes and other cell types in the tissue sample.

The fact that the same rearranged pattern has been generated on both the skin and blood specimens in three separate experiments indicates that the rearrangement is real and not likely to be an artefact of partial digestion. Moreover, the absence of the 11.0-kb EcoR1 fragment (Fig. 1, panel I) and the near absence of the 4.0-kb HindIII fragment (Fig. 1, panel III) are consistent with a deletional rearrangement of the $c \beta 1$ locus and indicate that DNA digestion had been complete. The presence of a rearranged band in the BamHI digest (Fig. 1, panel V) provides further evidence that rearrangement of the TCR- $\beta$ gene was indeed present.

In contrast, when the filters were hybridized to a TCR- $\gamma$ joining region probe to detect rearrangement of the TCR- $\gamma$ gene, no rearrangement was detected by any of the three restriction enzymes (Fig. 2). No rearrangement of the $\mathrm{Ig} \mathrm{H}$ chain gene in the patient's blood specimen could be detected (Fig. 3).

\section{DISCUSSION}

Our finding of the presence of TCR- $\beta$-chain gene rearrangement in the absence of TCR- $\gamma$-chain gene rearrangement in this case was unexpected. In search of possible explanations, we first considered the possibility that the TCR- $\gamma$ joining region probe used in this case might not detect all possible rearrangements of the

\section{Eco RI}

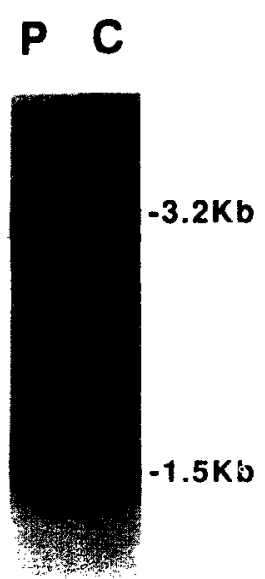

Hind III

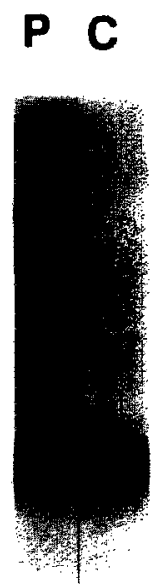

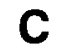

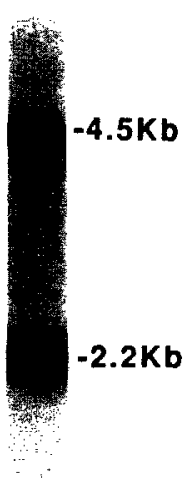

Bam HI

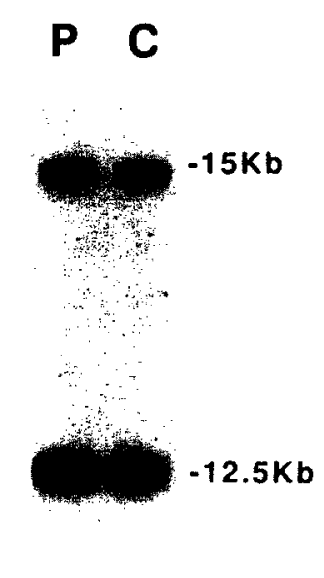

Fig. 2. Southern blot hybridization analysis of the $T$ cell receptor $\gamma$ chain genes (TCR- $\gamma$ ). DNA analysis of the patient's blood with the TCR- $\gamma$ joining region probe, jy1, after digestion with EcoR 1 , HindIII and BamHI. P represents the patient's specimen and $\mathrm{C}$ represents the control specimen. Dashes indicate germline bands in kilobases. No rearranged band is present. Two control lanes with HindIII are shown and represent a polymorphism site at the HindIII sequence in the TCR- $\gamma$ joining region. 

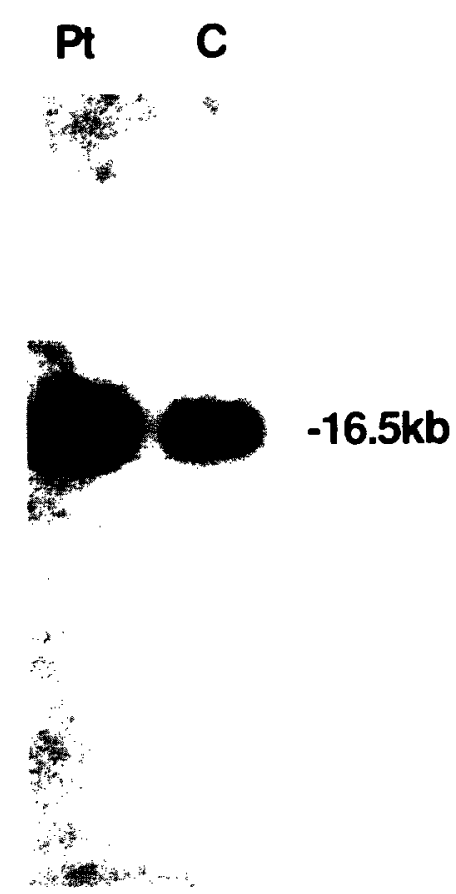

FIG. 3. Southern blot hybridization analysis of immunoglobulin heavy chain gene. DNA analysis of the patient's blood with the immunoglobulin heavy chain joining region probe, $\mathrm{jH}$, after digestion with BamHI. P represents the patient's specimen and $\mathrm{C}$ represents the control specimen. No rearranged band is present in the patient's specimen.

TCR- $\gamma$ gene. However, this is very unlikely, especially when three restriction enzymes were used. In particular, BamHI digestion generates large DNA fragments which envelop all the known joining regions so that any rearrangement of the TCR- $\gamma$-chain gene should be detectable by our probe (14).

Another explanation is that the malignant transformation of the $T$ cells in our patient might have deleted the TCR- $\gamma$-chain genes. Our experimental evidence, however, indicates that this has not occurred. As mentioned earlier, the malignant $T$ cells constitute a large fraction of the peripheral blood mononuclear cell population. If the TCR- $\gamma$-chain genes were deleted from these cells, we would expect a marked decrease in the amount of DNA that would hybridize with the TCR- $\gamma$ probe resulting in a significant reduction in the intensity of the bands on our blots. The fact that dense bands were present indicates that the TCR- $\gamma$-chain genes in the CTCL cell population were intact, and that the TCR- $\gamma$-chain region was in a germ line configuration.

Our patient has cutaneous $\mathrm{T}$ cell lymphoma. In this disease, it is believed that the malignant $T$ cells originate from $T$ cells with affinity for the skin. Whether these "cutaneous" $T$ cells are the same as other T cells is not known. As the skin is capable of producing various thymic hormones $(15-18)$ and cytokines $(19,20)$, it has been suggested that the skin may be an extrathymic site for $\mathrm{T}$ cell development $(16,21-23)$. It is conceivable that the cutaneous $T$ cells may have devel- 
oped and matured in the skin, bypassing the thymus, as has been suggested for murine Thy $-1^{+}$dendritic epidermal cells $(24,25)$. T cell ontogeny in this cutaneous microenvironment may not be as well regulated as in the thymus. Thus, the malignant $\mathrm{T}$ cells in our patient, having developed in the skin, may exhibit unusual patterns of gene rearrangement.

So far, there has not been an extended, systematic study of both TCR- $\beta$ - and $\gamma$-chain gene rearrangements in CTCL; most reported series have examined $\beta$-chain gene rearrangements only. Our limited experience on six other cases of CTCL has revealed a variety of rearrangement patterns. Four cases have rearrangements of both $\beta$ - and $\gamma$-chain genes; one case rearranged the $\gamma$-chain genes without rearrangement of the $\beta$-chain genes; and another case showed a $\gamma$-chain gene rearrangement and an equivocal $\beta$-chain gene rearrangement (data not shown).

A fourth possibility is that $T$ cells need not sequentially rearrange the TCR- $\gamma$ gene followed by the TCR- $\beta$ gene, as the current concepts of T cell ontogeny hold. Recently, some in vitro evidence has accumulated to suggest that TCR- $\gamma$ receptorbearing cells belong to a separate lineage distinct from the TCR- $\alpha / \beta$ receptorbearing cells $(25,26)$. Our finding in this case suggests that there are TCR- $\alpha / \beta$ receptor-binding cells that may totally bypass the $\gamma$ gene rearrangement process, thus lending support to the separate lineage concept.

In conclusion, our case demonstrates that TCR- $\beta$-chain gene rearrangement can occur in the absence of TCR- $\gamma$-chain gene rearrangement. This raises doubts in our current understanding of $\mathrm{T}$ cell ontogeny which depicts an orderly sequence of $\gamma / \delta$ gene rearrangements followed by $\alpha / \beta$-chain gene rearrangements. It also raises the interesting possibility that $T$ cells residing in the skin may undergo an altered sequence of TCR rearrangements and T cell differentiation.

\section{REFERENCES}

1. Pardoll, D. M., Fowlkes, B. J., Bluestone, J. A., et al., Differential expression of two distinct T-cell receptors during thymocyte development. Nature (London) 326, 79-81, 1987.

2. Foroni, L., Matutes, E., Foldi, J., et al., T-cell leukemias with rearrangement of the gamma but not beta T-cell receptor genes. Blood 71, 356-362, 1988.

3. Goorha, R., Bunin, N., Mirro, J., Jr., et al., Provocative pattern of rearrangements of the genes for the gamma and beta chains of the T-cell receptor in human leukemias. Proc. Natl, Acad. Sci. USA 84, 4547-4551, 1987.

4. Kimura, N., Du, R. P., and Mak, T. W., Rearrangement and organization of T cell receptor gamma chain genes in human leukemic T cell lines. Eur. J. Immunol. 17, 1653-1656, 1987.

5. Greenberg, J. M., Quertermous, T., Seidman, J. G., et al., Human T cell gamma-chain gene rearrangements in acute lymphoid and nonlymphoid leukemia: Comparison with the $T$ cell receptor beta-chain gene. J. Immunol. 137, 2043-2049, 1986.

6. Sangster, R. N., Minowada, J., Suciu-Foca, N., et al., Rearrangement and expression of the alpha, beta, and gamma chain $\mathrm{T}$ cell receptor genes in human thymic leukemia cells and functional T cells. J. Exp. Med. 163, 1491-1508, 1986.

7. Petersson, U., and Sambrook, J., Amount of viral DNA in the genome of cells transformed by adenovirus type 2. J. Mol. Biol. 73, 125-130, 1973.

8. Southern, E. M., Detection of specific sequences among DNA fragments separated by gel electrophoresis. J. Mol. Biol. 98, 503-517, 1975.

9. Feinberg, A. P., and Vogelstein, B.. A technique for radiolabeling DNA restriction endonuclease fragments to high specific activity. Anal. Biochem. 132, 6-13, 1983. 
10. Gupta, A. K., Fisher, G. J., Elder, J. T., et al., Sphingosine inhibits phorbol ester-induced inflammation, ornithine decarboxylase activity, and activation of protein kinase $\mathrm{C}$ in mouse skin. $J$. Invest. Dermatol. 91, 486-491, 1988.

11. Yanagi, Y., Yoshikai, Y., Leggett, K., et al., A human T cell-specific cDNA clone encodes a protein having extensive homology to immunoglobulin chains. Nature (London) 308, 145-149, 1984.

12. Lefranc, M. P., and Rabbitts, T. H., Two tandemly organized human genes encoding the T-cell gamma constant-region sequences show multiple rearrangement in different T-cell types. Nature (London) 316, 464-466, 1985.

13. Hanson, C. A., Frizzera, G., Patton, D. F., et al., Clonal rearrangement for immunoglobulin and T-cell receptor genes in systemic Castleman's disease: Association with Epstein-Barr virus. Amer. J. Pathol. 131, 84-91, 1988.

14. Lefranc, M. P., Forster, A., Baer, R., et al., Diversity and rearrangement of the human T cell rearranging gamma genes: Nine germ-line variable genes belonging to two subgroups. Cell 45, 237-246, 1986.

15. Rubenfeld, M. R., Silverstone, A. E., Knowles, J. P., et al., Induction of lymphocyte differentiation by epidermal cultures. J. Invest. Dermatol. 77, 221-224, 1981.

16. Edelson, R. L., Round cells of the epidermis: Clues from studies on neoplastic lymphocytes of cutaneous T cell lymphoma. J. Invest. Dermatol. 75, 95-102, 1980.

17. Safai, B., Good, R. A., Twomey, J. J., et al., A novel lymphocyte differentiating factor in serum of patients with mycosis fungoides and sezary syndrome. 54, 837-841, 1979.

18. Chu, A. C., Patterson, J. A. K., Goldstein, G., et al., Thymopoietin-like substance in human skin. J. Invest. Dermatol. 81, 194-197, 1983.

19. Kupper, T. S., Horowitz, M., Lee, F., et al., Molecular characterization of keratinocyte cytokines. J. Invest. Dermatol. 88, 501, 1987. [Abstract]

20. Sauder, D. N., Carter, C. S., Katz., S. I., et al., Epidermal cell production of thymocyteactivating factor (ETAF). J. Invest. Dermatol. 79, 34-39, 1982.

21. Kupper, T. S., and Edelson, R. L., The role of cytokines in the pathophysiology of T cell mediated skin disease. J. Dermatol. 14, 517-523, 1987.

22. Streillein, J. W., Skin-associated lymphoid tissues (SALT): Origins and functions. J. Invest. Dermatol. 80, 12s-16s, 1983.

23. Haynes, B. F., Scearce, R. M., Lobach, D. F., et al., Phenotypic characterization and ontogeny of mesodermal-derived and endocrine epithelial components of the human thymic microenvironment. J. Exp. Med. 4, 1149-1168, 1984.

24. Bergtresser, P. R., Sullivan, S., Streillein, J. W., et al., Origin and function of Thy-1 ${ }^{+}$dendritic epidermal cells in mice. J. Invest. Dermatol. 85, 85s-90s, 1985.

25. Stingl, G., Gunter, K. C., Tshachler, E., et al., Thy-1 ${ }^{+}$dendritic epidermal cells belong to the T-cell lineage. Proc. Natl. Acad. Sci. USA 84, 2430-2434, 1987.

26. Winoto, A., and Baltimore, D., Separate lineages of $T$ cells expressing the alpha-beta and gammadelta receptors. Nature (London) 338, 430-432, 1989.

Received April 4, 1989; accepted with revision September 29, 1989 